\title{
Influence of softening test and light-activation protocols on resin composite polymer structure
}

\author{
Maria Cecília Caldas Giorgi ${ }^{1}$, Débora Alves Nunes Leite Lima ${ }^{1}$, Giselle Maria Marchi ${ }^{1}$, \\ Gláucia Maria Ambrosano², Flávio Henrique Baggio Aguiar ${ }^{1}$
}

Correspondence: Dr. Maria Cecília Caldas Giorgi

'Department of Restorative Dentistry Piracicaba Dental School, University of Campinas, Piracicaba-SP, Brazil,

Email: cecilia.giorgi@yahoo.com 2Department of Social Dentistry, Piracicaba Dental School, University of Campinas, Piracicaba-SP, Brazil

\section{ABSTRACT}

Objective: This study analyzed the influences of the light-activation protocol and softening test on the degree of conversion (DC) and Knoop Hardness (KHN) of a microhybrid resin composite. Materials and Methods: Filtek Z250 (3M ESPE) was light-activated with a third-generation light-emitting diode (Valo Ultradent) by three protocols - standard, high power, and plasma emulation - or with a quartz-tungsten halogen XL 3000 (3M ESPE) in conventional mode. All modes were set to deliver $19 \mathrm{~J} / \mathrm{cm}^{2}$. The DC $(N=20)$ was determined by Fourier transform infrared spectrometry on the top (T) and bottom (B) surfaces. For the KHN test, samples were subdivided in four groups ( $n=5$ each) according to the storage media: absolute ethanol, $75 \%$ ethanol, distilled water, and air (control group). The KHN values were evaluated on T and B before and $24 \mathrm{~h}$ after immersion in the storage media. Data were analyzed by split-plot analysis of variance (ANOVA; for DC) or repeated-measures split-plot ANOVA (for KHN), followed by Tukey's test $(\alpha=0.05)$. Results: For the DC, the light-activation protocol did not influence the results and there was no difference between T and B. For the KHN test, the light-activation protocol did not influence the results and $\mathrm{T}$ showed higher microhardness values than $\mathrm{B}$ for all experimental conditions. There were significant differences in KHN depending on the storage media. Samples immersed in absolute ethanol generally presented lower KHN values, with no differences compared to samples in $75 \%$ ethanol. Conclusion: The storage media affected the outcomes of the softening test.

Key words: Dental light-curing, ethanol, hardness, polymerization

\section{INTRODUCTION}

Light-activated resin composites are widely used in dentistry. Since their introduction into the market, light-curing units (LCUs) have become a key equipment in dental offices. ${ }^{[1]}$ The polymerization reaction begins when light at the correct wavelength reaches the resin composite. This reaction involves the rupture of carbon-carbon double bonds $(\mathrm{C}=\mathrm{C})$ of dimethacrylate monomers into primary carbon-carbon single $(\mathrm{C}-\mathrm{C})$ covalent bonds, with a reduction in the intermolecular distances. ${ }^{[2]}$
The conversion of a monomer into a polymer, known as the degree of conversion (DC), is related to the performance of resin composite materials. When higher DCs are obtained, improved mechanical properties are achieved. Indeed, the monomer DC of photoactivated resin composites will increase over several hours, until vitrification hinders the further propagation of growing chains. ${ }^{[3]}$ Therefore, the monomer DC is never complete, and the formed polymer contains considerable quantities of unreacted $\mathrm{C}=\mathrm{C}$. This condition may lead to reduced mechanical properties, and may allow the free monomer to be eluted from the resin composite. ${ }^{[4]}$

\footnotetext{
How to cite this article: Giorgi MC, Lima DN, Marchi GM, Ambrosano GM, Aguiar FB. Influence of softening test and light-activation protocols on resin composite polymer structure. Eur J Dent 2014;8:9-14.

Copyright @ 2014 Dental Investigations Society. DOI: $10.4103 / 1305-7456.126233$
} 
Fourier transform infrared (FTIR) spectroscopy can be used to evaluate the DC of a resin composite directly. Nevertheless, when taken alone, this information does not fully characterize the polymer structure. The DC is an average measure that does not account for the heterogeneity of the material. ${ }^{[4]}$ Polymers that differ in linearity and, therefore, have different cross-link densities (CLDs) may have similar DCs. A cross-link forms when the radical reacts with a pendant $C=C$ on a different kinetic chain. Systems with very low cross-linking tend to be weak and flexible, whereas polymers with high degrees of cross-linking are hard, inflexible, and more heat resistant. The monomer structure influences a polymer's ultimate physical properties. ${ }^{[5]}$ The polymer CLD may be assessed by measuring the glass transition temperature ${ }^{[5,6]}$ and by softening tests. ${ }^{[7,8]}$ The softening test is easy to conduct and is based on repeated measurements before and after immersion of the samples in organic solvents. ${ }^{[8]}$

The aim of this study was to evaluate the influence of different softening storage media and light-activation protocols on the DC and CLD of a composite resin. The working hypotheses were: 1) different combinations of power density and exposure duration may affect the DC, microhardness, and CLD and 2) different storage media may show different capabilities for evaluating CLD.

\section{MATERIALS AND METHODS}

A microhybrid resin composite (Filtek Z50; 3M ESPE, St Paul, MN,USA) of A3 shade was selected for this study. The light-activation protocols were: Third light-emitting diode (LED) generation Valo (Ultradent Products, South Jordan, UT, USA) in three modes - standard (1000 $\left.\mathrm{mW} / \mathrm{cm}^{2}, 19 \mathrm{~s}\right)$, high power $\left(1400 \mathrm{~mW} / \mathrm{cm}^{2}, 14 \mathrm{~s}\right)$, and plasma emulation $\left(3200 \mathrm{~mW} / \mathrm{cm}^{2}, 6 \mathrm{~s}\right)$; and quartz-tungsten halogen XL 3000 (3M ESPE, Grafenau, Germany) in conventional mode $\left(500 \mathrm{~mW} / \mathrm{cm}^{2}, 38 \mathrm{~s}\right)$ - all set up to deliver approximately $19 \mathrm{~J} / \mathrm{cm}^{2}$.

Eighty cylindrical specimens $(N=20)$ were prepared in Teflon mold ( $5 \mathrm{~mm}$ in diameter, $2 \mathrm{~mm}$ thick). A transparent polyester strip was positioned on the bottom (B) of the mold. The cavity was filled in one increment. The top (T) was covered with another polyester strip to provide a flat surface and to remove a possible oxygen-inhibited layer, and the strip was covered with a glass plate. After that, the glass plate was removed, and the sample was polymerized according to the light-activation protocols described above.
After light activation, the sample was removed from the Teflon mold and submitted to the DC test on the $\mathrm{T}$ and B surfaces. For Knoop Hardness (KHN), the samples were subdivided into four groups ( $n=5$ each) according to the storage media: 1 ) absolute ethanol, 2) $75 \%$ ethanol,3) distilled water, and 4 ) air. The KHN test was performed before and after 24-h immersion in storage medium at $37^{\circ} \mathrm{C}$.

\section{Degree of conversion}

The DC measurements were recorded in absorbance mode with an FTIR spectrometer (Spectrum 100 FTIR; PerkinElmer, Waltham, MA, USA) coupled to a zinc selenide multiple (six) reflection attenuated total reflection (ATR) accessory, with a refraction index of 2.4 at $1000 \mathrm{~cm}^{-1}$ (Pick Technologies, Madison, WI, USA). A preliminary reading for the nonpolymerized resin composite was taken under the following conditions: $1665-1580 \mathrm{~cm}^{-1}$ frequency range, $4 \mathrm{~cm}^{-1}$ resolution, and Happ-Genzel apodization in absorbance mode. Additional FTIR spectra were obtained immediately after light activation performed according to the experimental groups.

The percentage of unreacted $\mathrm{C}=\mathrm{C}$ bonds was determined from the ratio of absorbance intensities of aliphatic $C=C$ bonds (peak at $1638 \mathrm{~cm}^{-1}$ ) against the internal standard (aromatic $\mathrm{C}=\mathrm{C}$ bonds, peak at $1608 \mathrm{~cm}^{-1}$ ). The DC was determined by the following formula:

$\mathrm{DC}(\%)=100 *\left[1-\mathrm{R}_{\text {polymerized }} / \mathrm{R}_{\text {nonpolymerized }}\right]$,

where $\mathrm{R}$ is the ratio of the band height at $1638 \mathrm{~cm}^{-1}$ to the band height at $1608 \mathrm{~cm}^{-1}$. Data were submitted to split-plot analysis of variance (ANOVA), followed by Tukey's test $(\alpha=0.05)$.

\section{Microhardness test and cross-link densitie evaluations}

The hardness at the bottom and top of each sample was obtained with a digital microhardness tester (HMV-2T E; Shimadzu Corporation, Tokyo, Japan) under a load of $10 \mathrm{~g}$ for $10 \mathrm{~s}$. Five hardness measurements were taken for the surface, and the KHN was recorded as the average of the five indentations. The hardness was determined before $\left(\mathrm{KHN}_{\mathrm{b}}\right)$ and after $\left(\mathrm{KHN}_{\mathrm{a}}\right)$ immersion in the storage media.

The CLD was estimated by the softening effect promoted by the storage media, that is, by the decrease in hardness. Data were submitted to repeated-measures split-plot ANOVA, followed by Tukey's test $(\alpha=0.05)$. 


\section{RESULTS}

\section{Degree of conversion}

The DC results are displayed in Table 1 . There were no statistically significant differences among the light-activation protocol $(P=0.0759)$ or surface factors $(P=0.295)$.

\section{Microhardness test and CLD evaluations}

The ANOVA showed a significant main effect for the surface and an interaction between storage media and microhardness [Table 2]. The T surfaces showed higher microhardness values than the $B$ surfaces, independent of the light-activation protocol or storage media before or after immersion. The $\mathrm{KHN}_{\mathrm{b}}$ values were higher than the $\mathrm{KHN}_{\mathrm{a}}$ values, irrespective of the storage media [Table 2], except for the groups stored in air (control groups). In the softening test, there were no significant differences in microhardness before immersion. After storage, the highest microhardness values were obtained when the samples were stored in air. Absolute ethanol showed higher or equal decreases in microhardness compared to

\begin{tabular}{lcc}
\hline \multicolumn{3}{l}{ Table 1: Results for degree of conversion (SD) } \\
\hline $\begin{array}{l}\text { Light-activation } \\
\text { protocol }\end{array}$ & Surface & DC \\
\hline XL 3000 conventional & T & $55.58(2.92) \mathrm{A}$ \\
& $\mathrm{B}$ & $55.79(2.28) \mathrm{A}$ \\
VALO standard & $\mathrm{T}$ & $56.3(4.72) \mathrm{A}$ \\
& $\mathrm{B}$ & $55.89(4.31) \mathrm{A}$ \\
VALO high power & $\mathrm{T}$ & $56.80(3.01) \mathrm{A}$ \\
& $\mathrm{B}$ & $57.25(3.55) \mathrm{A}$ \\
VALO plasma emulation mode & $\mathrm{T}$ & $56.81(3.49) \mathrm{A}$ \\
& $\mathrm{B}$ & $55.68(3.44) \mathrm{A}$ \\
\hline
\end{tabular}

DC: Degree of conversion, SD: Standard deviation, Lolute A provide prefix. Mean values with the same letter were not statistically different $(P<0.05)$

\begin{tabular}{|c|c|c|c|c|}
\hline \multirow{2}{*}{$\begin{array}{l}\text { Light- } \\
\text { activation } \\
\text { protocol }\end{array}$} & \multirow[t]{2}{*}{ Surface } & \multirow{2}{*}{$\begin{array}{l}\text { Storage } \\
\text { media }\end{array}$} & \multicolumn{2}{|c|}{ Microhardness } \\
\hline & & & $\mathrm{KHN}_{\mathrm{b}}(\mathrm{SD})$ & $\mathrm{KHN}^{\mathrm{a}}$ (SD) \\
\hline \multirow[t]{6}{*}{$\begin{array}{l}\mathrm{XL} 3000 \\
\text { conventional }\end{array}$} & $T$ & $\begin{array}{l}\text { Distilled } \\
\text { water }\end{array}$ & $\begin{array}{c}* 37.24(9.93) \\
\mathrm{Aa}\end{array}$ & $\begin{array}{c}{ }^{*} 29.90(9.45) \\
\mathrm{Bb}\end{array}$ \\
\hline & & $\begin{array}{l}75 \% \\
\text { Ethanol }\end{array}$ & $\begin{array}{c}* 39.16(8.59) \\
\mathrm{Aa}\end{array}$ & $\begin{array}{c}* 32.19(3.24) \\
\mathrm{Bbc}\end{array}$ \\
\hline & & $\begin{array}{l}\text { Absolute } \\
\text { ethanol } \\
100\end{array}$ & $\begin{array}{c}* 43.23(7.91) \\
\mathrm{Aa}\end{array}$ & $\begin{array}{c}\star^{*} 25.08(2.12) \\
\text { Bc }\end{array}$ \\
\hline & & Air & $\begin{array}{c}\star 37.18(6.57) \\
\mathrm{Aa}\end{array}$ & $\begin{array}{c}\text { *40.02 (7.68) } \\
\mathrm{Aa}\end{array}$ \\
\hline & B & $\begin{array}{l}\text { Distilled } \\
\text { water }\end{array}$ & $\begin{array}{c}30.91(8.64) \\
\mathrm{Aa}\end{array}$ & $\begin{array}{c}27.84(9.53) \\
\mathrm{Bb}\end{array}$ \\
\hline & & $\begin{array}{l}75 \% \\
\text { Ethanol }\end{array}$ & $\begin{array}{c}40.86(8.10) \\
\mathrm{Aa}\end{array}$ & $\begin{array}{c}32.11(1.52) \\
\mathrm{Bbc}\end{array}$ \\
\hline
\end{tabular}

Contd...

\begin{tabular}{|c|c|c|c|c|}
\hline & & $\begin{array}{l}\text { Absolute } \\
\text { ethanol } \\
100\end{array}$ & $\begin{array}{c}40.51(8.49) \\
\mathrm{Aa}\end{array}$ & $\begin{array}{c}24.28(4.68) \\
\mathrm{BC}\end{array}$ \\
\hline & & Air & $\begin{array}{c}33.34(9.58) \\
\mathrm{Aa}\end{array}$ & $\begin{array}{c}37.76(6.52) \\
\mathrm{Aa}\end{array}$ \\
\hline \multirow[t]{8}{*}{$\begin{array}{l}\text { VALO } \\
\text { standard }\end{array}$} & $\mathrm{T}$ & $\begin{array}{l}\text { Distilled } \\
\text { water }\end{array}$ & $\begin{array}{c}* 39.99(6.95) \\
\mathrm{Aa}\end{array}$ & $\begin{array}{c}\text { *33.09 }(5.80) \\
\mathrm{Bb}\end{array}$ \\
\hline & & $\begin{array}{l}75 \% \\
\text { Ethanol }\end{array}$ & $\begin{array}{c}\text { *38.38 (10.34) } \\
\mathrm{Aa}\end{array}$ & $\begin{array}{c}{ }^{*} 25.83(10.14) \\
\text { Bbc }\end{array}$ \\
\hline & & $\begin{array}{l}\text { Absolute } \\
\text { ethanol } \\
100\end{array}$ & $\begin{array}{c}{ }^{*} 2.92(6.90) \\
\mathrm{Aa}\end{array}$ & $\begin{array}{c}{ }^{\star} 24.84(7.16) \\
\text { Bc }\end{array}$ \\
\hline & & Air & $\begin{array}{c}\text { *39.72 (5.06) } \\
\mathrm{Aa}\end{array}$ & $\begin{array}{c}* 40.18(13.57) \\
\mathrm{Aa}\end{array}$ \\
\hline & B & $\begin{array}{l}\text { Distilled } \\
\text { water }\end{array}$ & $\begin{array}{c}34.02(5.68) \\
\mathrm{Aa}\end{array}$ & $\begin{array}{c}33.32(5.15) \\
\mathrm{Bb}\end{array}$ \\
\hline & & $\begin{array}{l}75 \% \\
\text { Ethanol }\end{array}$ & $\begin{array}{c}34.74(9.05) \\
\mathrm{Aa}\end{array}$ & $\begin{array}{c}21.48(6.57) \\
\mathrm{Bbc}\end{array}$ \\
\hline & & $\begin{array}{l}\text { Absolute } \\
\text { ethanol } \\
100\end{array}$ & $\begin{array}{c}34.81(5.62) \\
\mathrm{Aa}\end{array}$ & $\begin{array}{c}19.10(5.50) \\
\text { Bc }\end{array}$ \\
\hline & & Air & $\begin{array}{c}38.42(6.64) \\
\mathrm{Aa}\end{array}$ & $\begin{array}{c}40.35(4.30) \\
\mathrm{Aa}\end{array}$ \\
\hline \multirow[t]{8}{*}{$\begin{array}{l}\text { VALO high } \\
\text { power }\end{array}$} & $\mathrm{T}$ & $\begin{array}{l}\text { Distilled } \\
\text { water }\end{array}$ & $\begin{array}{c}* 39.55(10.20) \\
\mathrm{Aa}\end{array}$ & $\begin{array}{c}* 34.00(12.40) \\
\mathrm{Bb}\end{array}$ \\
\hline & & $\begin{array}{l}75 \% \\
\text { Ethanol }\end{array}$ & $\begin{array}{c}* 36.52(10.92) \\
\mathrm{Aa}\end{array}$ & $\begin{array}{c}{ }^{*} 28.46(7.05) \\
\text { Bbc }\end{array}$ \\
\hline & & $\begin{array}{l}\text { Absolute } \\
\text { ethanol } \\
100\end{array}$ & $\begin{array}{c}\text { *39.11 (7.47) } \\
\mathrm{Aa}\end{array}$ & $\begin{array}{c}{ }^{*} 26.72(4.28) \\
\text { Bc }\end{array}$ \\
\hline & & Air & $\begin{array}{c}* 42.45(4.22) \\
\mathrm{Aa}\end{array}$ & $\begin{array}{c}* 43.40(7.22) \\
\mathrm{Aa}\end{array}$ \\
\hline & B & $\begin{array}{l}\text { Distilled } \\
\text { water }\end{array}$ & $\begin{array}{c}38.83(9.55) \\
\mathrm{Aa}\end{array}$ & $\begin{array}{c}33.09(10.47) \\
\mathrm{Bb}\end{array}$ \\
\hline & & $\begin{array}{l}75 \% \\
\text { Ethanol }\end{array}$ & $\begin{array}{c}37.09(5.82) \\
\mathrm{Aa}\end{array}$ & $\begin{array}{c}24.85(4.11) \\
B b c\end{array}$ \\
\hline & & $\begin{array}{l}\text { Absolute } \\
\text { ethanol } \\
100\end{array}$ & $\begin{array}{c}37.07 \text { (8.55) } \\
\mathrm{Aa}\end{array}$ & $\begin{array}{c}22.09(7.68) \\
\text { Bc }\end{array}$ \\
\hline & & Air & $\begin{array}{c}38.98(6.75) \\
\mathrm{Aa}\end{array}$ & $\begin{array}{c}39.81(4.27) \\
\mathrm{Aa}\end{array}$ \\
\hline \multirow[t]{8}{*}{$\begin{array}{l}\text { VALO plasma } \\
\text { emulation }\end{array}$} & $\mathrm{T}$ & $\begin{array}{l}\text { Distilled } \\
\text { water }\end{array}$ & $\begin{array}{c}* 36.58(7.89) \\
\mathrm{Aa}\end{array}$ & $\begin{array}{c}\text { *33.58 (6.79) } \\
\mathrm{Bb}\end{array}$ \\
\hline & & $\begin{array}{l}75 \% \\
\text { Ethanol }\end{array}$ & $\begin{array}{c}* 35.88(7.96) \\
\mathrm{Aa}\end{array}$ & $\begin{array}{c}* 30.17(8.90) \\
\text { Bbc }\end{array}$ \\
\hline & & $\begin{array}{l}\text { Absolute } \\
\text { ethanol } \\
100\end{array}$ & $\begin{array}{c}* 37.96(9.66) \\
\mathrm{Aa}\end{array}$ & $\begin{array}{c}{ }^{*} 26.47(8.19) \\
\text { Bc }\end{array}$ \\
\hline & & Air & $\begin{array}{c}* 34.29(2.10) \\
\mathrm{Aa}\end{array}$ & $\begin{array}{c}* 35.01(9.36) \\
\mathrm{Aa}\end{array}$ \\
\hline & B & $\begin{array}{l}\text { Distilled } \\
\text { water }\end{array}$ & $\begin{array}{c}35.79(11.22) \\
\mathrm{Aa}\end{array}$ & $\begin{array}{c}31.14(8.62) \\
\mathrm{Bb}\end{array}$ \\
\hline & & $\begin{array}{l}75 \% \\
\text { Ethanol }\end{array}$ & $\begin{array}{c}27.82(5.81) \\
\mathrm{Aa}\end{array}$ & $\begin{array}{c}27.23(8.23) \\
\mathrm{Bbc}\end{array}$ \\
\hline & & $\begin{array}{l}\text { Absolute } \\
\text { ethanol } \\
100\end{array}$ & $\begin{array}{c}34.13(6.80) \\
\mathrm{Aa}\end{array}$ & $\begin{array}{c}23.23(8.49) \\
\text { Bc }\end{array}$ \\
\hline & & Air & $\begin{array}{c}31.07(10.11) \\
\mathrm{Aa}\end{array}$ & $\begin{array}{c}32.80(8.30) \\
\mathrm{Aa}\end{array}$ \\
\hline
\end{tabular}

Mean values followed by different case letters (uppercase in row, lowercase in column) were statistically different $(P<0.05)$. ${ }^{*}$ Differs from bottom surface inside the same light-activation protocol, storage media, and microhardness 
water and $75 \%$ ethanol. Samples stored in distilled water presented $\mathrm{KHN}_{\mathrm{a}}$ values that were different from the values obtained for samples stored in absolute ethanol.

\section{DISCUSSION}

The aim of this investigation was to evaluate the influence of different light-activation protocols and storage media on the DC and microhardness values of a microhybrid resin composite.

In the history of adhesive dentistry, two main technologies of LCUs and several light-curing protocols have been proposed to promote effective polymerization. Effective polymerization of the adhesive bond system and resin composite is required to obtain long-term clinical success. ${ }^{[9]}$ The quality of the network formed during polymerization will dictate the extent to which molecular uptake and swelling occur when a polymer is submerged in an organic solvent, ${ }^{[10]}$ which is the condition present in the oral cavity.

The LED LCU used in this study delivered light at three irradiances, all in continuous mode: Standard $\left(1000 \mathrm{~mW} / \mathrm{cm}^{2}\right)$, high power $\left(1400 \mathrm{~mW} / \mathrm{cm}^{2}\right)$, and plasma emulation $\left(3200 \mathrm{~mW} / \mathrm{cm}^{2}\right)$. The continuous mode delivers the same power density without interruption throughout the entire exposure period. ${ }^{[11]}$ Although an extremely high irradiance is generated in plasma emulation mode, this high irradiance is not obtained by the generation of a plasma field, as it is for PAC LCUs (plasma arc light-curing units). Instead, according to the manufacturer, the high irradiance is generated by high-powered LED chips, which boost the light output to levels that, in some cases, surpass that of PAC lights. The PAC LCUs were developed in an attempt to decrease the polymerization time, reducing the time needed to cure resin composites from $30-40 \mathrm{~s}$ to $3 \mathrm{~s} \cdot{ }^{[12]}$ However, some reports have demonstrated that this approach is more costly, shows more shrinkage and stress, and generates more heat, which could injure the pulp. ${ }^{[13]}$

The light-activation protocols used in this study did not affect the DC of the tested resin composite [Table 1]. This finding is in agreement with the results from other studies that used different curing protocols with similar energy densities and did not find differences in DC. ${ }^{[3,4,7,14]}$ The energy density used was sufficient to attain a DC between $55 \%$ and $57 \%$, without achieving statistically significant differences between the $T$ and $B$ surfaces. This result may be explained by the fact that samples were $2 \mathrm{~mm}$ in height, which is an acceptable thickness for light-curing resin composites based on methacrylate. ${ }^{[15,16]}$

In all of the conditions evaluated, the T surfaces presented higher hardness values than the $B$ surfaces [Table 2]. During the light-activation process, the light that passes through the resin composite is absorbed and scattered. Thus, the light intensity is attenuated, and its effectiveness is reduced as the depth increases. ${ }^{[17,18]}$ For this test, the effect of light scattering was noted, which promoted a decrease in light transmittance along the bulk of material. Consequently, less energy reached the bottom surface, ${ }^{[9,19]}$ resulting in a less cross-linked polymer on that surface. Clinically, this result means that the light activation of a 2-mm increment resulted in a heterogenic material, with decreased cross-linking along the bulk of the material. As a result, the B surface polymer will be more susceptible to organic solvents.

After $24 \mathrm{~h}$ of immersion in storage media, differences were detected in $\mathrm{KHN}_{\mathrm{a}}$. The effects of chemical solvents vary, but typically involve an elution of unreacted components and some degradative effect on the polymer network. ${ }^{[10]}$ In the present study, except for samples stored in air, all experimental conditions showed significant differences from the initial measurement $\left(\mathrm{KHN}_{\mathrm{b}}\right)$. Samples stored in absolute or $75 \%$ ethanol showed higher decreases in hardness, thus presenting similar behaviors. When ethanol penetrates the polymer network, it causes an expansion of the structure, allowing a softening of the resin composite surface by removing the polymer structure as unreacted monomer, oligomers, and linear polymers. ${ }^{[4,14]}$ This expansion is facilitated when the CLD is low because the solvent can disrupt secondary interchain bonds, but not primary cross-link bonds. ${ }^{[5]}$ The reduction in hardness is a consequence of polymer plasticization. ${ }^{[10]}$

In the present work, there was no difference between absolute ethanol and $75 \%$ ethanol. This finding is not consistent with the results of a previous study ${ }^{[8]}$ which showed that the ethanol concentration affected polymer softening. The discrepancy between these studies may be explained by the immersion time. In the present study, the samples were light activated and immediately immersed in storage media. In other studies, ${ }^{[7-9]}$ the immersion in the softening test occurred after $24 \mathrm{~h}$ of dry storage. Immediate immersion favored the solvent action, and both 
absolute ethanol and 75\% ethanol showed similar behaviors. Absolute ethanol had a higher potential to dissolve the polymer network than water. Samples stored in distilled water showed a lower potential to decrease the hardness than absolute ethanol and presented no significant difference compared to $75 \%$ ethanol. Dental polymer networks absorb aqueous solvents to the extent of several percentage points of their total weight. There is a general trend for the sorption of ethanol/water solutions to be greater than that of water alone. ${ }^{[10]}$ Thus, different storage media present different abilities to evaluate CLD.

The light-activation protocol showed no differences in the microhardness test $(P=0.3706)$. All of the curing protocols delivered energy continuously at a minimum of $500 \mathrm{~mW} / \mathrm{cm}^{2} / \mathrm{s}$, and no significant differences were noticed. This quantity of irradiance probably sensitizes several photoinitiator molecules, initiating a multitude of growth centers and resulting in a polymer with a higher CLD. ${ }^{[7]}$ Within the conditions of this study, the absence of differences among light-activation protocols indicates that above $500 \mathrm{~mW} / \mathrm{cm}^{2}$, the initiation process might reach a plateau. This result is not in agreement with that of a study ${ }^{[20]}$ that evaluated the effect of four different light-curing protocols (standard, high irradiance, pulse delay, and soft-start) on the microtensile bond strength, ultimate bond strength, KHN, and CLD of nanohybrid resin composite samples. This previous study concluded that a soft-start protocol might improve the ultimate tensile strength and KHN without compromising the resin-dentine microtensile bond strength. However, soft-start and pulse delay protocols may reduce the CLD of the resin composite polymeric network. ${ }^{[20]}$

The plasma emulation mode, which delivered a very high irradiance in a short time, was expected to result in a polymer with poor structure. The rapid initiation of polymerization could induce shorter chain lengths, thereby leading to a lower molecular weight and compromising the physical and mechanical properties of resin composite materials. ${ }^{[21]}$ The results of the present study do not corroborate this idea. This discrepancy might be explained by the 6-s exposure time used, which differed from the 3-s exposure time commonly used in PAC LCUs. Thus, the extended exposure time probably allowed the activation of more growth centers, resulting in a network with longer chain lengths and higher CLDs. However, further studies should evaluate the consequences of this very high-power and short-time protocol on the shrinkage stress and temperature increases.

In summary, the present findings showed that different light-activation protocols delivering the same energy density did not influence the DC on either the T or B surfaces of 2-mm samples. However, they did affect the KHN values according to the surface. Top surfaces showed higher KHN values in all experimental conditions, supporting the idea that the bottom surfaces are usually more critical areas. Although the energy density was delivered by different protocols, these different protocols did not result in polymers with distinct solvent susceptibilities. Absolute ethanol and 75\% ethanol showed higher potentials for analyzing the polymer structure than other softening solutions.

\section{REFERENCES}

1. Jiménez-Planas A, Martín J, Abalos C, Llamas R. Developments in polymerization lamps. Quintessence Int 2008;39:e74-84.

2. Peutzfeldt A. Resin composite in dentistry: The monomer systems. Eur J Oral Sci 1997;105:97-116.

3. Gonçalves F, Calheiros FC, Witzel MF, Kawano Y, Braga RR. Effect of photoactivation protocol and radiant exposure on monomer conversion and flexural strength of a resin composite after water and ethanol storage. J Biomed Mater Res B Appl Biomater 2007;82:89-92.

4. Asmussen E, Peutzfeldt A. Influence of selected components on crosslink density in polymer structures. Eur J Oral Sci 2001;109:282-5.

5. Soh MS, Yap AU. Influence of curing modes on crosslink density in polymer structures. J Dent 2004,32:321-6.

6. Dewaele M, Asmussen E, Peutzfeldt A, Munksgaard EC, Benetti AR, Finné $\mathrm{G}$, et al. Influence of curing protocol on selected properties of light-curing polymers: Degree of conversion, volume contraction, elastic modulus, and glass transition temperature. Dent Mater 2009;25:1576-84.

7. Asmussen E, Peutzfeldt A. Influence of pulse-delay curing on softening of polymer structures. J Dent Res 2001;80:1570-3.

8. Schneider LF, Moraes RR, Cavalcante LM, Sinhoreti MA, Correr-Sobrinho L, Consani S. Cross-link density evaluation through softening tests: Effect of ethanol concentration. Dent Mater 2008;24:199-203.

9. Aguiar FH, Braceiro AT, Ambrosano GM, Lovadino JR. Hardness and diametrical tensile strength of a hybrid composite resin polymerized with different modes and immersed in ethanol or distilled water media. Dent Mater 2005;21:1098-103.

10. Ferracane JL. Hygroscopic and hydrolytic effects in dental polymer networks. Dent Mater 2006;22:211-22.

11. Benetti AR, Asmussen E, Munksgaard EC, Dewale M, Peutzfeldt A, Leloup G, et al. Softening and elution of monomers in ethanol. Dent Mater 2009;25:1007-13.

12. Bagis B, Bagis Y, Ertas E, Ustaomer S. Comparison of the heat generation of light curing units. J Contemp Dent Pract 2008;9:65-72.

13. Moon HJ, Lee YK, Lim BS, Kim CW. Effects of various light curing methods on the leachability of uncured substances and hardness of a composite resin. J Oral Rehabil 2004;31:258-64.

14. Witzel MF, Calheiros FC, Gonçalves F, Kawano Y, Braga RR. Influence of photoactivation method on conversion, mechanical properties, degradation in ethanol and contraction stress of resin-based materials. J Dent 2005;33:773-9.

15. Yap AU. Effectiveness of polymerization in composite restoratives claiming bulk placement: Impact of cavity depth and exposure time. Oper Dent 2000;25:113-20. 
16. Price RB, Dérand T, Loney RW, Andreou P. Effect of light source and specimen thickness on the surface hardness of resin composite. Am J Dent 2002;15:47-53.

17. Watts DC. Reaction kinetics and mechanics in photo-polymerised networks. Dent Mater 2005;21:27-35.

18. dos Santos GB, Alto RV, Filho HR, da Silva EM, Fellows CE. Light transmission on dental resin composites. Dent Mater 2008;24:571-6.

19. Arikawa $\mathrm{H}$, Fujii K, Kanie T, Inoue K. Light transmittance characteristics of light-cured composite resins. Dent Mater 1998;14:401-11.

20. Feitosa VP, Fugolin AP, Correr AB, Correr-Sobrinho L, Consani S, Watson TF, et al. Effects of different photo-polymerization protocols on resin-dentine $\mu \mathrm{TBS}$, mechanical properties and cross-link density of a nano-filled resin composite. J Dent 2012;40:802-9.

21. Hubbezoğlu I, Bolayir G, Doğan OM, Doğan A, Ozer A, Bek B.
Microhardness evaluation of resin composites polymerized by three different light sources. Dent Mater J 2007;26:845-53.

\begin{tabular}{|l|l|}
\hline \multicolumn{2}{|c|}{ Access this article online } \\
\hline Quick Response Code: & $\begin{array}{l}\text { Website: } \\
\text { www.eurjent.com }\end{array}$ \\
\cline { 2 - 2 } & $\begin{array}{l}\text { Source of Support: This study } \\
\text { was supported by Coordenação de } \\
\text { Aperfeiçoamento de Pessoal de Nível } \\
\text { Superior -CAPES - Brasil } \\
\text { Conflict of Interest: None declared }\end{array}$ \\
\end{tabular}

